\title{
Perceptions of Climate Change
}

27 March 2011

This past winter, for the second year in a row, seemed pretty extreme in both Europe and the United States. So this is a good time to check quantitatively how seasonal climate change is stacking up against expectations.

People's perception of climate change may be the most important factor determining their willingness to accept the scientific conclusion that humans are causing global warming (or global climate disruption, as you please). It is hard to persuade people that they have lying eyes.

In the paper attached to my congressional testimony in 1988 (1) we asserted that the perceptive person would notice that climate was changing by the early $21^{\text {st }}$ century. I used colored dice to illustrate how the frequency of unusually warm seasons was expected to change.

We considered three scenarios for future greenhouse gas amounts. Figure 1 shows that the real world so far is close to scenario $\mathrm{B}$. Temporary aside: there are two main reasons that greenhouse gas growth moved off the track of scenario A onto scenario B in the early 1990s, as shown in Figure 2: (1) the growth of CFCs (chlorofluorocarbons) was greatly diminished by successive tightenings of the Montreal Protocol, (2) the growth of methane slowed sharply.

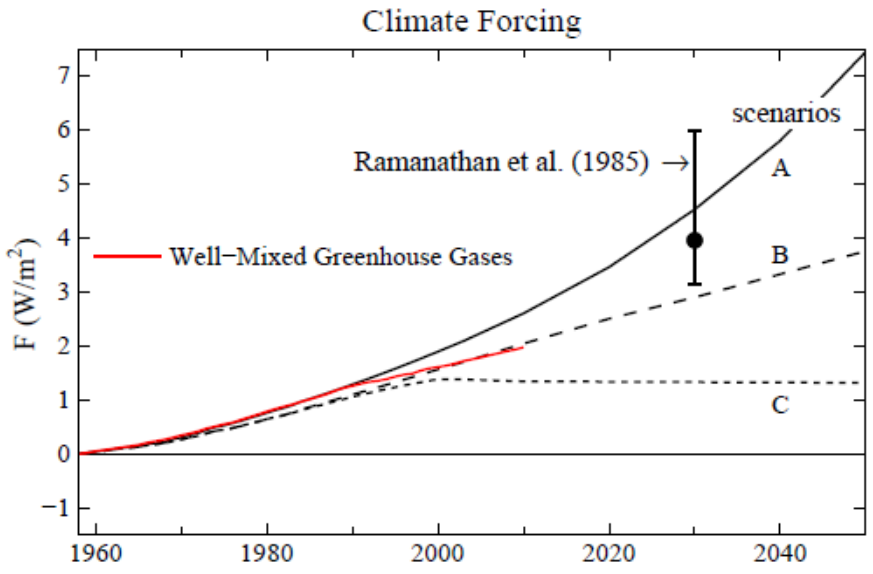

Fig. 1. Update of Fig. 2 of Reference 1, scenarios A, B and C being climate forcings of greenhouse gases used in climate model simulations. The real world (red curve) has closely followed scenario B.

(a) Annual $\mathrm{CO}_{2}$ Growth

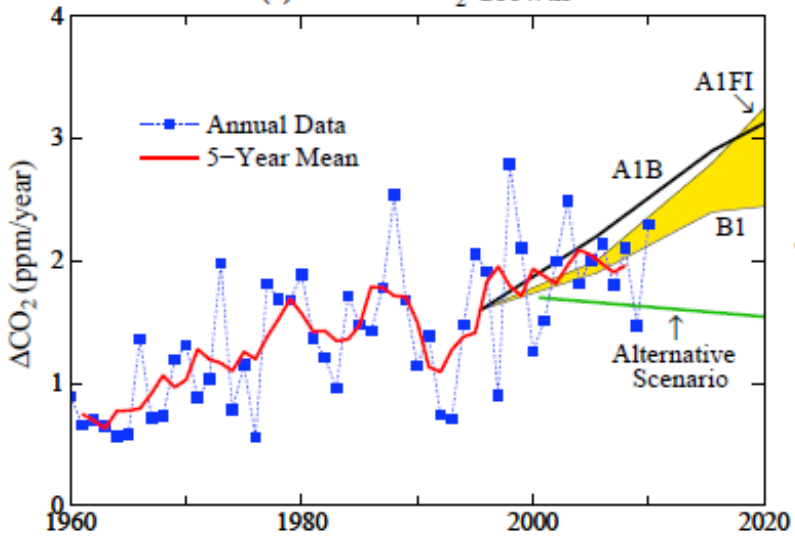

(b) Greenhouse Gas Forcing Growth Rates

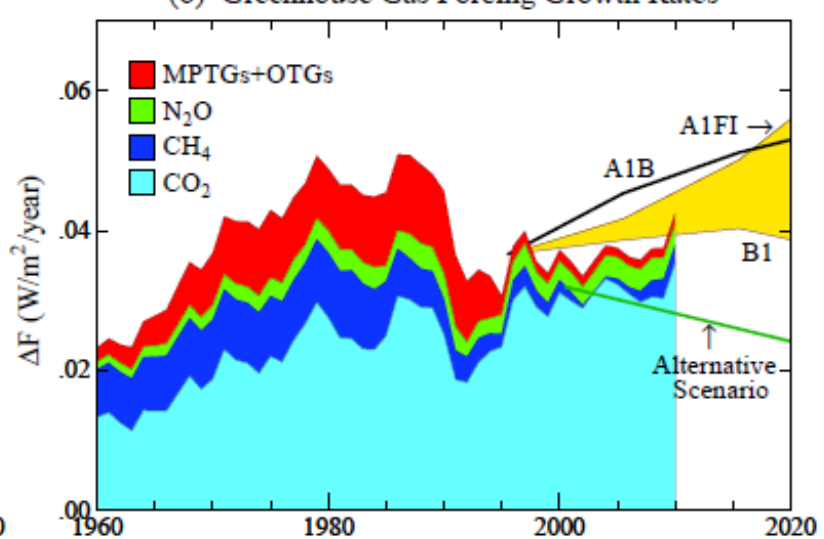

Fig.2. Annual growth of (a) $\mathrm{CO}_{2}$ and (b) climate forcing by greenhouse gases. The forcing is the 5-year running mean, except final two points, for 2009 and 2010, are 3-year and 1-year means. See reference 2. 


\section{Winter 2011 Surface Temperature Anomalies $\left({ }^{\circ} \mathrm{C}\right)$ : Base Period $=1951-1980$}

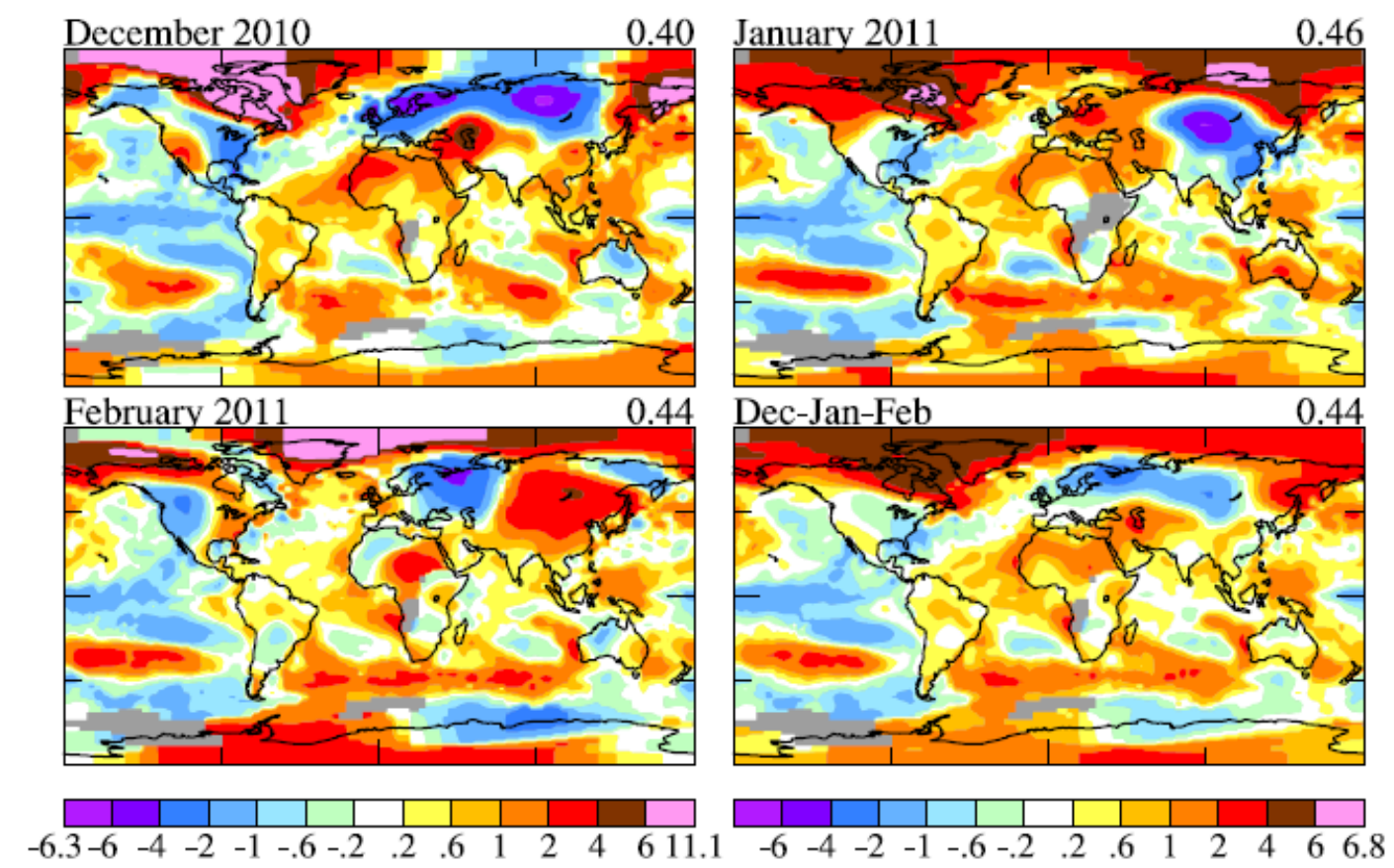

Fig. 3. Surface temperature anomalies in Northern Hemisphere winter 2010-2011 relative to 1951-1980 mean. See reference 3 .

Let's start with this past winter, compare it with the last few winters, and then check whether the odds of warm seasons have changed as expected. Figure 3 shows the temperature anomaly for each of the past three months and the seasonal (Dec-Jan-Feb) mean anomaly.

December was very warm in northeast Canada, about $10^{\circ} \mathrm{C}$ (about $15-20^{\circ} \mathrm{F}$ ) warmer than baby-boomers' climatology (1951-1980 mean). It was unusually cold in the eastern United States and especially in northern Eurasia. Hudson Bay and Baffin Bay (between Canada and Greenland) were essentially ice-free, the first recorded time that ice-free conditions lasted so long. Ice-free water is a huge potential source of heat to the atmosphere. When the water is icecovered the air above the ice can sink to 10 or $20^{\circ} \mathrm{C}$ below zero, but ice-free water warms the air above. I speculated in a prior post that this energy source may have contributed to causing the long-wave patterns that pushed cold Arctic air into northern Eurasia. But before getting carried away with regional climate prediction, let's compare the last few winters and summers.

Figure 4 shows the seasonal mean temperature anomalies for the prior three Northern Hemisphere winters and the mean for the past decade. Note that the Northern Hemisphere temperature anomaly pattern in 2010 (Dec 2009, Jan-Feb 2010) was very similar to 2011, including the unusually warm Hudson Bay region. The similarity occurred despite the opposite phases of the Southern Oscillation in the equatorial Pacific Ocean, 2010 having an El Niño and 2011 having a La Niña. But the strong patterns are averaged out in the mean anomaly for the first decade of this century. The decadal mean has widespread warming of about $1^{\circ} \mathrm{C}$, but greater warming in the Arctic and less warming in the southern and western United States.

Figure 5 shows seasonal temperature anomalies for the last three Northern Hemisphere summers and the mean anomaly for the past decade. The United States was about half a degree Celsius (about $1^{\circ} \mathrm{F}$ ) warmer in summers of the past decade compared to 1951-1980. Europe was $1-2^{\circ} \mathrm{C}$ warmer, in what seems to be downwind extension of large warming in northern Africa. 
Dec-Jan-Feb Surface Temperature Anomalies $\left({ }^{\circ} \mathrm{C}\right)$ : Base Period $=1951-1980$
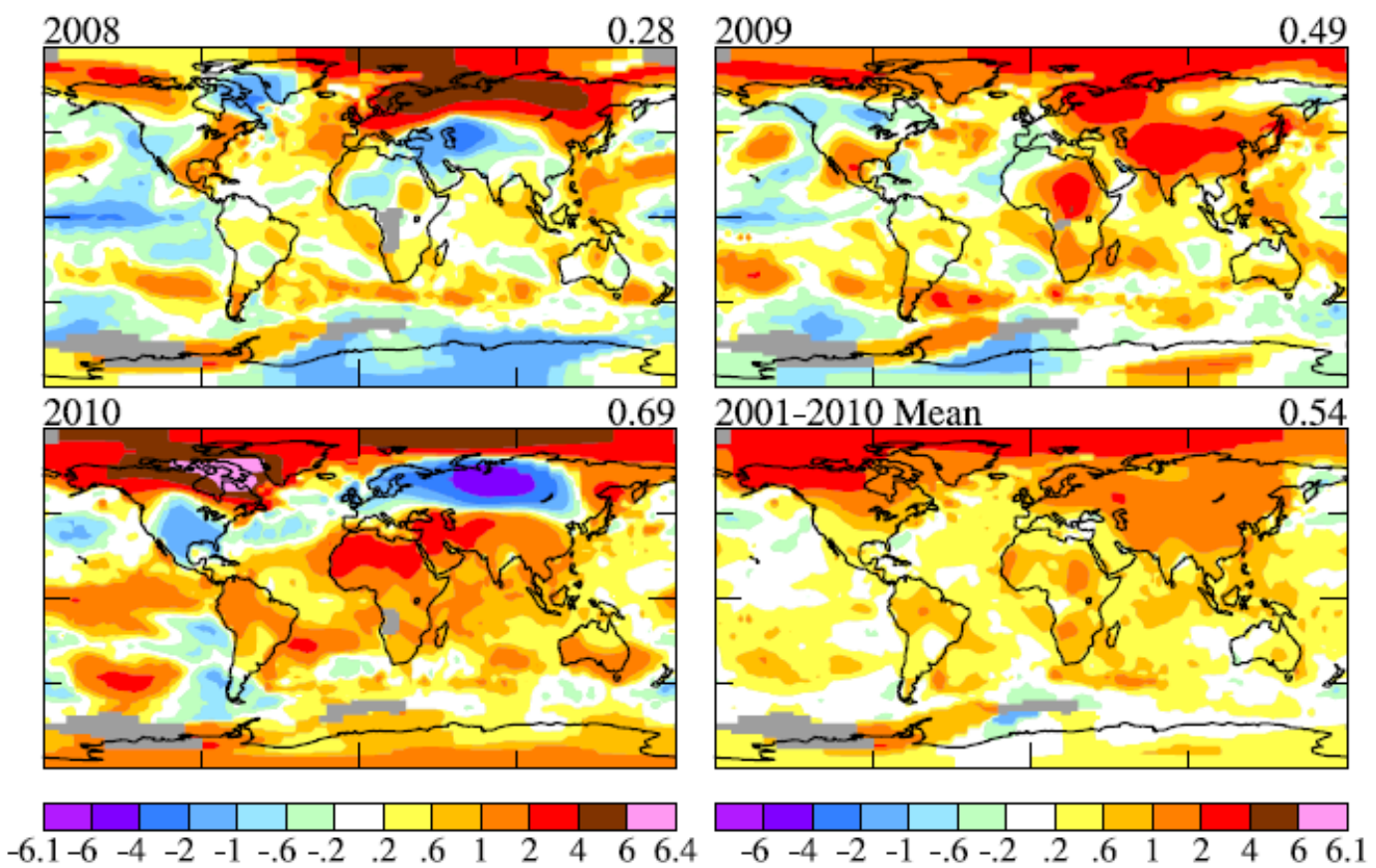

Fig. 4. Surface temperature anomalies in the prior three Northern Hemisphere winters and the mean anomaly for the past decade. See reference 3.

Jun-Jul-Aug Surface Temperature Anomalies $\left({ }^{\circ} \mathrm{C}\right)$ : Base Period $=1951-1980$
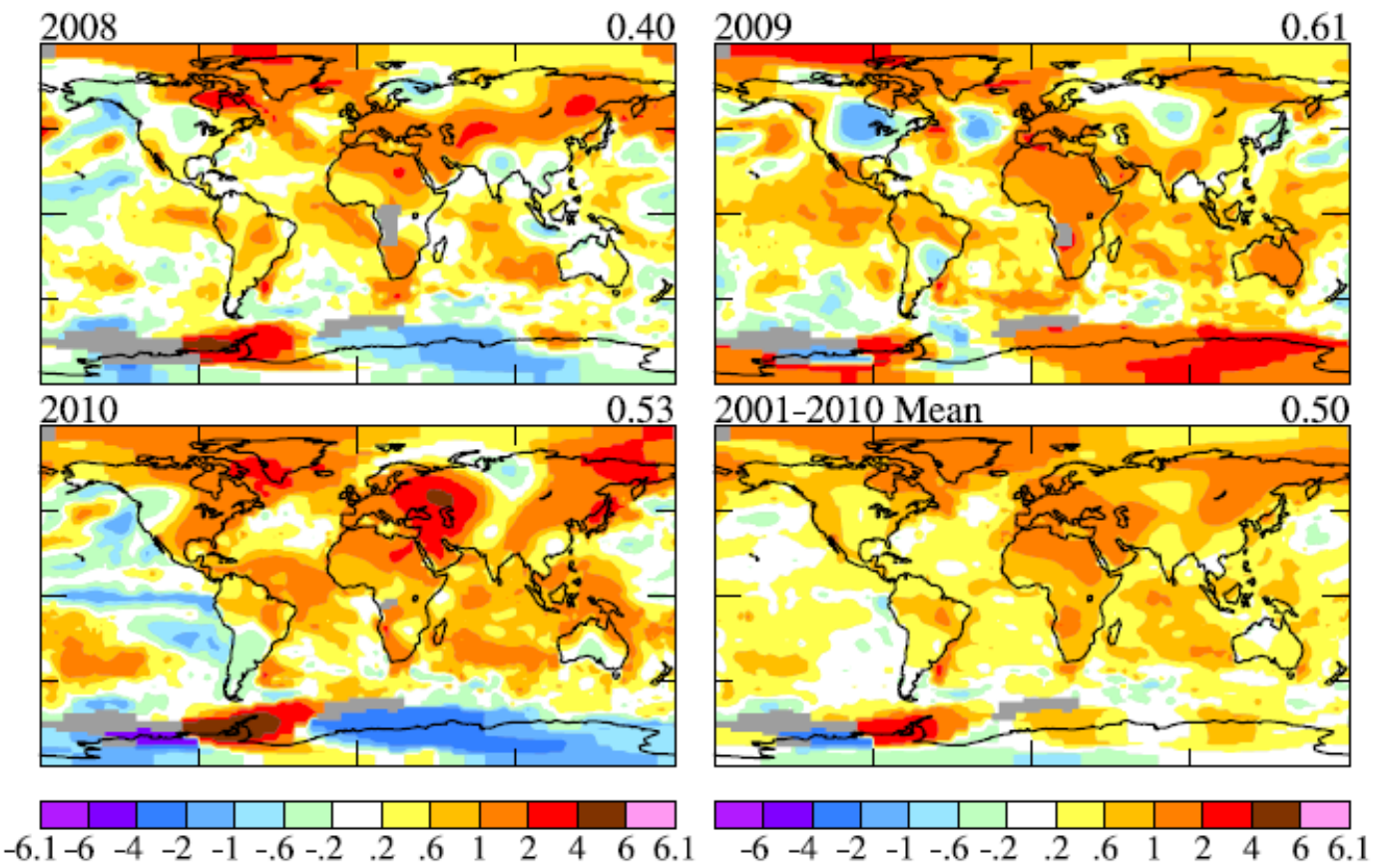

Fig. 5. Surface temperature anomalies in the last three Northern Hemisphere summers and the mean anomaly for the past decade. See reference 3 . 


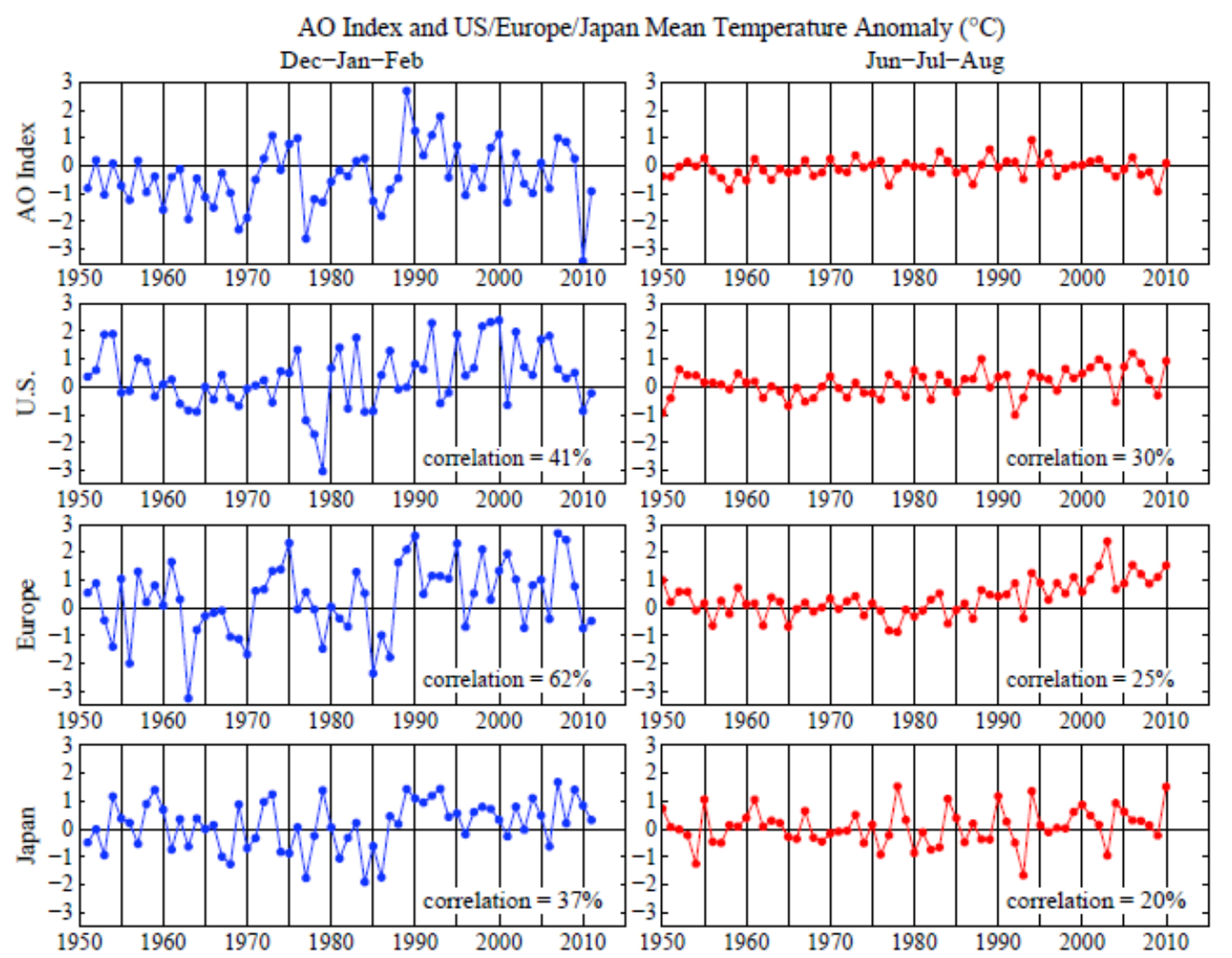

Fig. 6. Arctic oscillation index (top row) for Dec-Jan-Feb and Jun-Jul-Aug, and corresponding seasonal mean temperature anomalies in the United States, Europe and Japan. See reference 3.

Before betting any money on seasonal predictions, let's look at one more piece of data. Figure 6 shows the Arctic oscillation index for Dec-Jan-Feb and Jun-Jul-Aug. When the AO index is negative Arctic surface pressure is high, which tends to cause cold air outbreaks, pushing Arctic air into middle latitudes. The AO index has high correlation (62\%) with European winter temperature, and weaker but significant correlations for the United States (41\%) and Japan (37\%). The correlations are much weaker in the summer, as expected given the weaker latitudinal temperature gradient.

Both the United States and Europe were colder than the 1951-1980 mean during each of the last two winters. But note that, despite all the belly-aching that we heard from Europe, it was only a bit colder than climatology. There were many winters that were much colder in 19511980, and even a few in the 1980s. Memories seem to be short. Of the last 10 winters 8 of 10 have been warmer than the 1951-1980 mean in the United States, 8 of 10 in Japan, and 6 of 10 in Europe. In the summer it is 8 of 10 in the United States, 8 of 10 in Japan, and 10 of 10 in Europe. But let's still hold off on any betting until we check on our climate dice of the 1980s. In reference (1), in approximation of categories used by the then United States Weather Service, we defined the 10 warmest summers of the 30 in 1951-1980 as "hot", the 10 coolest as "cold", and the middle 10 as "normal". Our climate simulations indicated that for greenhouse gas scenario B the frequency of "hot" summers would increase to about $60 \%$ in the first decade of the $21^{\text {st }}$ century and $70 \%$ in the second decade. In other words, instead of two sides of the die being red, it was expected to become four red sides at about the present time. 

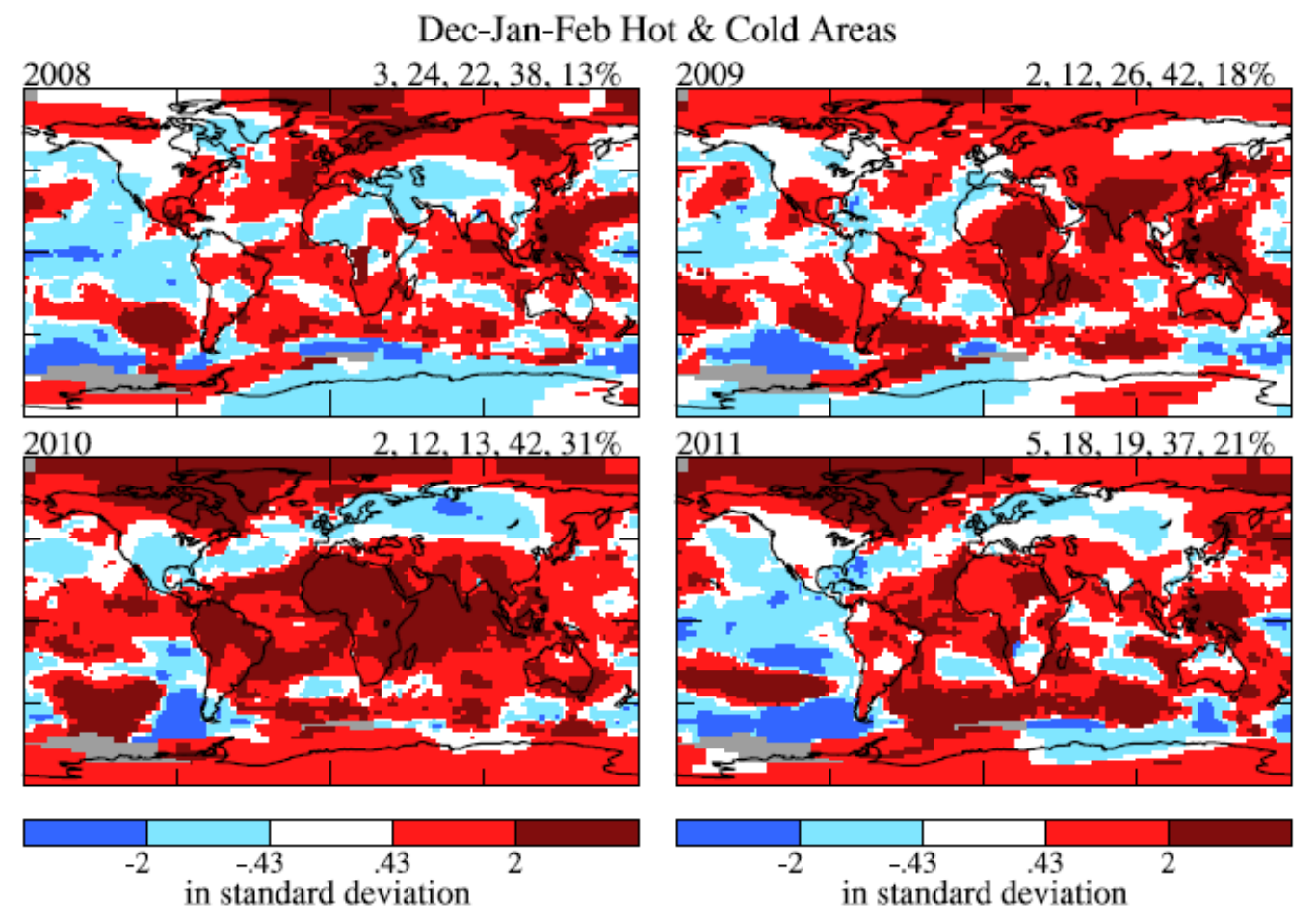

Fig. 7. Dec-Jan-Feb "hot" and "cold" areas during the past four years, with hot and cold defined by the 1951-1980 climatology. Dark blue and black are areas of extreme cold and heat, extremes of a magnitude that occurred $2-3 \%$ of the time in the period of climatology. See reference 1.

Now we can check the degree to which the real world has lived up to this expectation. The answer will vary from one place to another, so let's make a global map for this past winter. Each gridbox will be colored red, white or blue, depending on how the local temperature this past winter compared with the categories established by the 1951-1980 climatology.

Figure 7 shows the result for the last four winters (summers in the Southern Hemisphere). To make the maps even more useful we use dark blue and dark red to show those places in which the temperature fell in the extreme ( $>2$ standard deviations) category that occurred only a few percent of the time in the period of climatology ${ }^{1}$. The extreme cases are important because those are the ones that have greatest practical implications, especially for nature. Species are adapted to climate of the past, so a change to more extreme climates can be detrimental, especially if it occurs so rapidly that species cannot migrate to stay within tolerable climatic conditions.

The numbers on the top of the maps are the percent of the area falling in the five categories: very cold, cold, normal, hot, very hot. In the period of climatology those numbers averaged $2 \%, 31 \%$, 33\%, 31\%, $2 \%$, rounded to the nearest percent.

Figure 7 reveals, for example, that the past two winters in Northern Europe both fell in the category of "cold" winters, but not extreme cold. The area hot or very hot (51-73\%) far exceeded the area with cold or very cold conditions in all four years (14-27\%).

Figure 8 shows results for Jun-Jul-Aug for each of the past four years. In both Jun-JulAug and Dec-Jan-Feb it is apparent that the area falling in either the hot or very hot category totals $64-78 \%$ in agreement with our 1988 climate simulations.

\footnotetext{
${ }^{1}$ Given the small number of extreme data points, we assumed a normal distribution for the temperature anomalies in the period of climatology; in that case $2.3 \%$ of cases exceed $+2 \sigma$ and another $2.3 \%$ exceed $-2 \sigma$.
} 

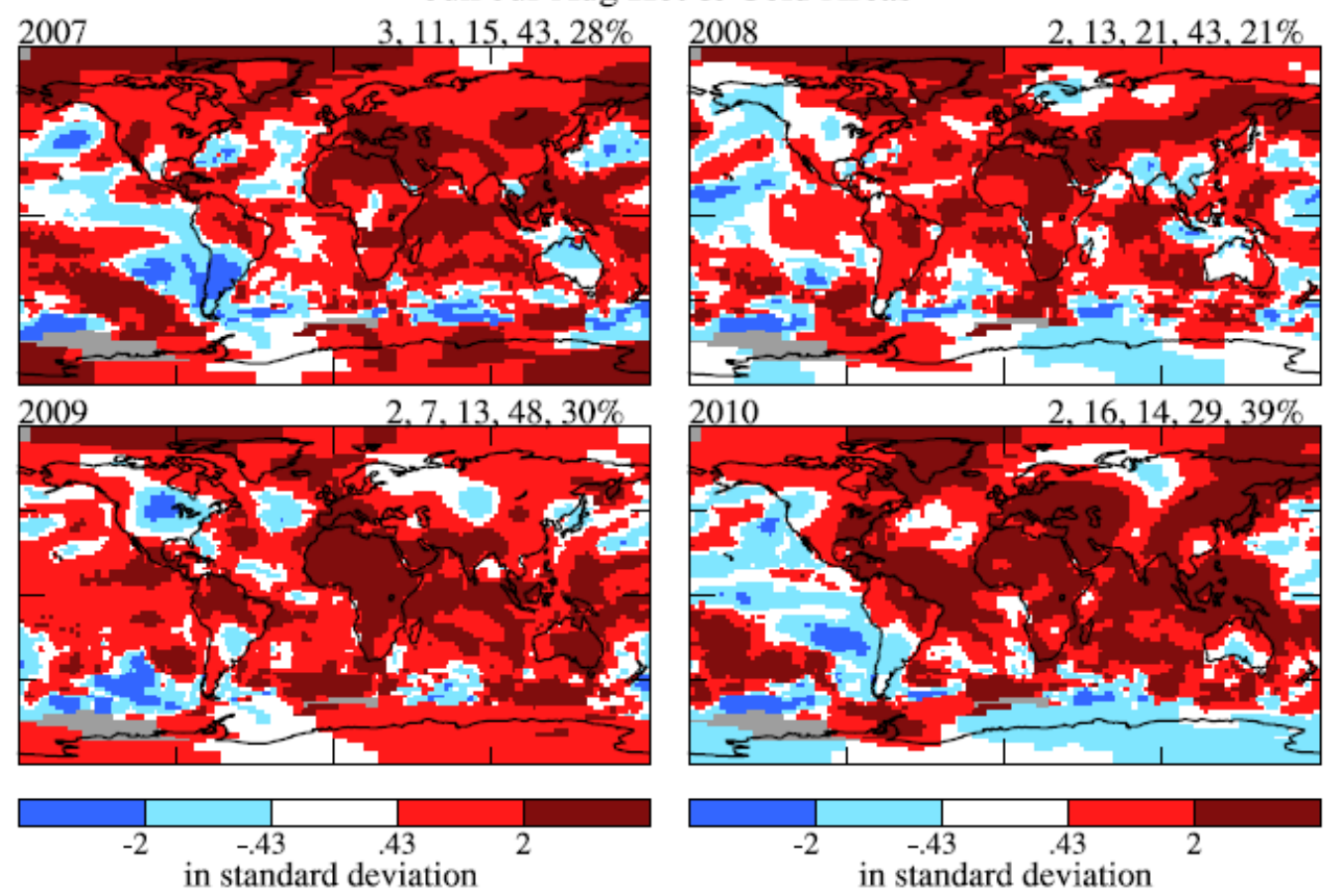

Fig. 8. Jun-Jul-Aug "hot" and "cold" areas during the past four years, with hot and cold defined by the 1951-1980 climatology. Dark blue and black are areas of extreme cold and heat, extremes of a magnitude that occurred $2-3 \%$ of the time in the period of climatology. See reference 1.

The perceptive person who is old enough should be able to recognize that the frequency of unusually mild winters is now much greater than it was in the period 1951-1980. But mild winters may not have much practical impact. So a return to one or two colder than average winters may affect the public's perception of climate change. On the other hand, the huge increase in the area with extremely hot summers, from 2-3\% in 1951-1980 to as much as 30-40 percent in recent years and most of the land area in 2010. If people cannot recognize that summers are becoming more extreme they may need to have their senses examined or their memories. Perhaps the people who do not recognize climate change are living in air conditioned environments, which are restricted mainly to one species.

As for specific areas affected most, we would not expect the climate model employed in 1988, which had coarse resolution and a simple representation of the ocean, to do a good job of predicting the spatial distribution of the largest warming signal. Yet Plate 2 of reference 1, showing a map of simulated early $21^{\text {st }}$ century temperature change divided by the standard deviation, compares very well with Figures 7 and 8, the signal being most apparent in the tropical ocean, sea ice regions, northern and central Africa, and the Amazon region. The model responded in that way because the ocean mixed layer is thinnest at low latitudes, and thus warms most rapidly there, and warming is amplified in regions where sea ice is lost.

O.K., now let's see what bets we can make, starting with next winter: are Europe and the United States going to be unusually cold again? Sea ice cover is very low now, as low as it has been in the period of satellite data. If low sea ice cover has caused the climate disruption of recent winters, as some scientists have asserted, that should hold again next winter, right? And I suggested that the ice-free Hudson and Baffin Bays were related to cold Europe. But were the long waves (the jet stream waggles) where they were because Hudson Bay was ice-free, or was 
Hudson Bay ice-free because the chaotic jet stream waggles happened to be where they were, causing southerly winds over Hudson Bay? Given the high degree of chaos in the AO index (see Fig. 15 in reference 3), I would not bet anything on Europe or United States winter temperature. On the long run the tendency, as verified by Figure 6 above, is toward winters that are warmer than climatology, so that is the direction I would lean, but I usually only bet on sure things, or on almost sure things that people find surprising.

One sure bet is that this decade will be the warmest in history. Yes, some scientists assert that there is decadal variability and the next decade or two could be cooler. How do we know they are wrong? Because, as we show in reference 4, the planet is now out of balance by about $3 / 4$ of a watt per square meter of Earth's surface averaged over the solar cycle. It may not sound like much, but that is a lot of energy (in an interesting unit suggested in a colleague's paper, Sarah Purkey and Greg Johnson?), the $3 / 4 \mathrm{~W} / \mathrm{m}^{2}$ corresponds, assuming a global populations of 7 billion, to every man, woman, and child on the planet running simultaneously 40 industrial strength 1400 watt hair dryers 24 hours a day 365 days a year). This energy is enough to cause the ocean to slowly warm and ice to melt all over the planet.

Sometimes it is interesting to make a bet that looks like it is high risk, but really isn't. Such a bet can be offered at this point. The NOAA web pages giving weekly ENSO updates (http://www.cpc.ncep.noaa.gov/products/analysis monitoring/lanina/enso evolution-status-fcsts-web.pdf) predict a return to ENSO-neutral conditions by mid-summer with some models suggesting a modest El Nino to follow. We have been checking these forecasts weekly for the past several years, and have noted that the models almost invariably are biased toward weak changes. Based on subsurface ocean temperatures, the way these have progressed the past several months, and comparisons with development of prior El Ninos, we believe that the system is moving toward a strong El Nino starting this summer. It's not a sure bet, but it is probable.

Finally, we can mention one other high probability bet, relevant to a Congressional hearing later this week. Dr. J. Scott Armstrong, a marketing professor at the Wharton School, University of Pennsylvania will testify about climate change to a committee of the House of Representatives. Armstrong, we are told, has made a bet that a prediction of no temperature change over a 10-year period starting in 2007 will prove more accurate than predictions of global warming. Observations (Figure 21 of Reference 3) show a linear warming rate over the past 50 years of $0.17^{\circ} \mathrm{C}$ per decade. Our climate model slows this down to about $0.15^{\circ} \mathrm{C}$ for the near future because of the change in GHG growth shown in Figure 2(b) above. That bet, warming of $0.15^{\circ} \mathrm{C} /$ decade would have a high probability of winning over a bet of no temperature change.

James Hansen and Makiko Sato

\section{References}

1. Hansen, J., I. Fung, A. Lacis, D. Rind, S. Lebedeff, R. Ruedy, G. Russell, 1988: Global climate changes as forecast by Goddard Institute for Space Studies three-dimensional model, $J$. Geophys. Res., 93, 9341-9364.

2. Hansen, J., M. Sato, 2004: Greenhouse gas growth rates, Proc. Natl. Acad. Sci., 101, 16109.

3. Hansen, J., R. Ruedy, M. Sato, K. Lo, 2010: Global surface temperature change, Rev. Geophys., 48, RG4004, 29 pp.

4. Hansen, J., M. Sato, P. Kharecha, K. von Schuckmann, 2011: Earth's energy imbalance and implications, draft paper. 